\title{
Wpływ techniki ściegu odpuszczającego na spawalność stali S355G10+N pod wodą
}

\author{
Effect of temper bead welding on weldability \\ of S355G10+N steel under water
}

\section{Streszczenie}

W artykule scharakteryzowano idee spawania mokrego oraz stosowania techniki ściegów odpuszczających. Przedstawiono wpływ zastosowania techniki ściegu odpuszczającego na skłonność stali podwyższonej wytrzymałości S355G10+N do pękania zimnego wyrażoną twardością strefy wpływu ciepła w warunkach spawania podwodnego. Badania przeprowadzono na próbkach spawanych techniką mokrą elektrodami otulonymi (MMA). W wyniku zrealizowanych badań wykazano, iż zastosowana technika w przypadku konieczności spawania naprawczego konstrukcji oceanotechnicznych ze stali S355G10+N może prowadzić do istotnej poprawy własności złączy.

Słowa kluczowe: spawanie pod wodą, spawanie mokre, stal o podwyższonej wytrzymałości, spawalność, pękanie zimne

\begin{abstract}
The article describes the wet welding and the temper bead welding techniques. The effect of the application of temper bead welding on the susceptibility of S355G10+N high strength steel to cold cracking expressed by hardness of the heat affected zone in underwater welding conditions was presented. Research were carried out on wet welded samples made with coated electrodes (MMA). Realized studies showed, that the temper bead welding technique, in the case of the repair welding of underwater S355G10+N steel structures, can lead to significant improvements in properties of joints.
\end{abstract}

Keywords: underwater welding, wet welding, high strength steel, weldability, cold cracking

\section{Wstęp}

Do spawania podwodnego najczęściej wykorzystuje się technikę mokrą elektrodami otulonymi, podczas której powstające złącze oraz łuk elektryczny mają bezpośredni kontakt z wodą [1 $\div 4$ ]. Największym problemem podczas spawania stali w warunkach podwodnych jest skłonność do tworzenia pęknięć zimnych [3,5 10]. Środowisko wodne znacznie ogranicza możliwość zastosowania tradycyjnych metod zmniejszenia podatności stali do pękania [1]. Jednym z niewielu dostępnych sposobów ograniczenia skłonności stali do powstawania pęknięć zimnych pod wodą jest zastosowanie techniki ściegu odpuszczającego [11 12]. Polega ona na określonym nakładaniu dodatkowych ściegów wewnątrz spoiny lub na jej warstwę licową, co powoduje miejscową obróbkę cieplną wcześniej położonych ściegów oraz stre-

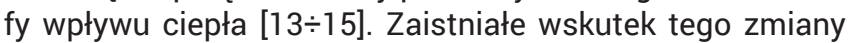
w strukturze prowadzą do zmniejszenia twardości w SWC złącza. Istnieje wiele odmian technik ściegu odpuszczającego, które najczęściej stosowane są dla złączy elementów o dużej grubości, gdy nie istnieje możliwość przeprowadzenia obróbki cieplnej złączy [13,14]. Obszar zastosowania tej techniki obejmuje głównie spawanie naprawcze procesami MMA i FCAW instalacji ze stali w przemyśle energetycznym.
Zgodnie z przepisami ASME należy nakładać sześć warstw, przy czym dla pierwszych trzech zaleca się wprowadzanie do złącza rosnącej ilości ciepła [13]. Aspektami determinującymi przydatność techniki ściegu odpuszczającego są przede wszystkim ilość wprowadzonego ciepła w każdym ze ściegów, odległość między ich osiami (podziałka) oraz czas pomiędzy położeniem ściegów odpuszczanego i odpuszczającego $[6,11 \div 14]$.

\section{Badania własne}

Celem pracy było określenie wpływu zastosowania techniki ściegu odpuszczającego na skłonność stali o podwyższonej wytrzymałości do tworzenia pęknięć zimnych podczas spawania mokrego elektrodami otulonymi. Do realizacji badań wykorzystano drobnoziarnistą stal S355G10+N o grubości $18 \mathrm{~mm}$. W celu zweryfikowania danych zawartych w świadectwie odbioru blachy przeprowadzono analizę składu chemicznego metodą spektrometrii emisyjnej ze wzbudzeniem iskrowym. W tablicy I zaprezentowano skład chemiczny stali, natomiast w tablicy II jej własności mechaniczne.

Dr inż. Dariusz Fydrych, mgr inż. Jacek Tomków, dr inż. Grzegorz Rogalski, dr hab. inż. Jerzy Łabanowski, prof. nadzw. PG - Politechnika Gdańska. 
Do wykonania napoin próbnych wykorzystano stanowisko do spawania pod wodą wyposażone w źródło prądu spawania ESAB Aristo 400. Napoiny wykonano na głębokości $20 \mathrm{~cm}$ elektrodami rutylowymi ogólnego przeznaczenia do spawania we wszystkich pozycjach OMNIA (E 380 R 11) o średnicy $4 \mathrm{~mm}$. Skład chemiczny oraz własności mechaniczne zastosowanych elektrod przedstawiono w tablicy III.

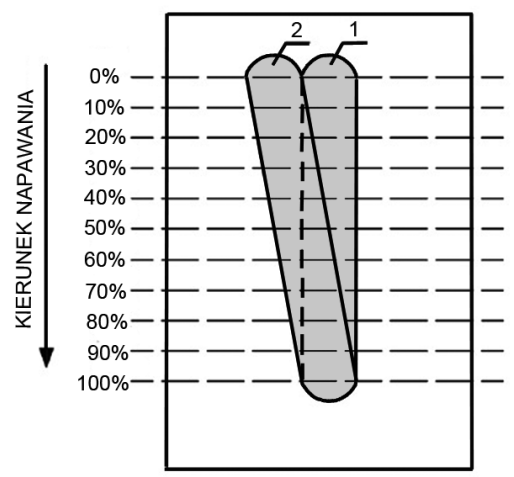

Rys. 1. Sposób wykonania napoin próbnych i pobrania próbek do badań Fig. 1. The method of test pad welding and cutting samples for tests
Badania przeprowadzono zgodnie z metodyką zaproponowaną w pracy [14] i z powodzeniem zastosowaną we wcześniejszych badaniach [11]. Z badanej blachy przygotowano odcinki o wymiarach $100 \times 200 \mathrm{~mm}$. Następnie wykonano na nich napoiny pod wodą elektrodami OMNIA w pozycji podolnej z biegunowością DC-. Napawanie polegało na wykonaniu nierównoległych napoin według schematu pokazanego na rysunku 1, na którym zaznaczono również sposób pobrania próbek do badań metalograficznych i twardości. Wykonano dwie płyty napawane zachowując czas między wykonaniem napoin 215 s (tablica IV).

\section{Badania metalograficzne}

Badania metalograficzne makroskopowe i mikroskopowe przeprowadzono zgodnie z wytycznymi zawartymi w normie [17]. Głównym celem badań makroskopowych była ocena stopnia nałożenia (podziałki) ściegu odpuszczającego na ścieg odpuszczany. Podczas badań makroskopowych (rys. 2) wykryto również występowanie niezgodności spawalniczych: pęcherzy gazowych (rys. 2b) oraz pęknięć wzdłuż linii wtopienia (ujawnione w przypadku jednej próbki - rys. 2d).

Tablica I. Skład chemiczny stali S355G10+N

Table I. Chemical composition of S355G10+N steel

\begin{tabular}{|c|c|c|c|c|c|c|c|c|c|c|c|c|c|}
\hline \multicolumn{14}{|c|}{ Zawartość pierwiastka, \% } \\
\hline $\begin{array}{l}\text { skład } \\
\text { chemiczny }\end{array}$ & C & $\mathrm{Si}$ & $\mathrm{Mn}$ & $\mathrm{P}$ & $S$ & $\mathrm{Cr}$ & Mo & $\mathrm{Ni}$ & Al & $\mathrm{Cu}$ & $\mathrm{Ti}$ & B & $\mathrm{Ce}_{\text {MIS }}$ \\
\hline $\begin{array}{l}\text { wg analizy } \\
\text { kontrolnej }\end{array}$ & 0,11 & \multirow[b]{2}{*}{0,35} & 1,39 & 0,008 & 0,005 & 0,017 & 0,018 & 0,246 & 0,039 & 0,27 & 0,003 & 0,001 & 0,384 \\
\hline $\begin{array}{c}\text { wg } \\
\text { świadectwa } \\
\text { odbioru }\end{array}$ & 0,09 & & 1,58 & 0,010 & 0,002 & 0,03 & 0,02 & 0,29 & 0,032 & 0,26 & 0,002 & 0,003 & 0,400 \\
\hline
\end{tabular}

Tablica II. Własności mechaniczne stali S355G10+N wg PN-EN 10225:2004 [16]

Table II. Mechanical properties of S355G10+N steel

\begin{tabular}{|c|c|c|}
\hline Granica plastyczności Re, MPa & Wytrzymałość na rozciąganie Rm, MPa & Wydłużenie A, \% \\
\hline$>355$ & $470 \div 630$ & $>22$ \\
\hline
\end{tabular}

Tablica III. Skład chemiczny oraz własności mechaniczne elektrod Omnia

Table III. Chemical composition and mechanical properties of Omnia electrodes

\begin{tabular}{|c|c|c|c|c|c|}
\hline \multicolumn{3}{|c|}{ Skład chemiczny, \% } & \multicolumn{3}{c|}{ Własności mechaniczne } \\
\hline C & Mn & Si & Re, MPa & Rm, MPa & A, \% \\
\hline 0,07 & 0,5 & 0,5 & 430 & 480 & 26 \\
\hline
\end{tabular}

Tablica IV. Parametry napawania próbek techniką ściegu odpuszczającego

Table IV. Conditions of temper bead welding tests

\begin{tabular}{|c|c|c|c|c|c|c|c|}
\hline Nr próbki & Napoina & $\begin{array}{l}\text { Natężenie } \\
\text { prądu } \\
\text { spawania } \\
\text { I, A }\end{array}$ & $\begin{array}{c}\text { Napięcie } \\
\text { łuku, } \\
\text { U, V }\end{array}$ & $\begin{array}{c}\text { Czas } \\
\text { spawania, } \\
\text { t, s }\end{array}$ & $\begin{array}{c}\text { Długość } \\
\text { napoiny I, } \\
\text { mm }\end{array}$ & $\begin{array}{l}\text { Prędkość } \\
\text { spawania } \\
\text { v, cm/min }\end{array}$ & $\begin{array}{c}\text { Energia } \\
\text { liniowa } \\
\text { spawania, } \\
\text { q, kJ/mm }\end{array}$ \\
\hline \multirow{2}{*}{ TBW1 } & 1 & 168 & 24,3 & 30 & 145 & 29,00 & 0,84 \\
\hline & 2 & 196 & 26,3 & 25 & 150 & 36,00 & 0,86 \\
\hline \multirow{2}{*}{ TBW2 } & 1 & 164 & 26,0 & 37 & \multirow{2}{*}{155} & 25,14 & 1,02 \\
\hline & 2 & 220 & 29,3 & 27 & & 34,44 & 1,12 \\
\hline
\end{tabular}


Badania metalograficzne mikroskopowe wykonano przy użyciu mikroskopu NEOPHOT 2 na zgładach trawionych $4 \%$ nitalem. Na rysunku 3 oznaczono obszary napoin, w których przeprowadzono badania mikroskopowe oraz pomiary twardości.
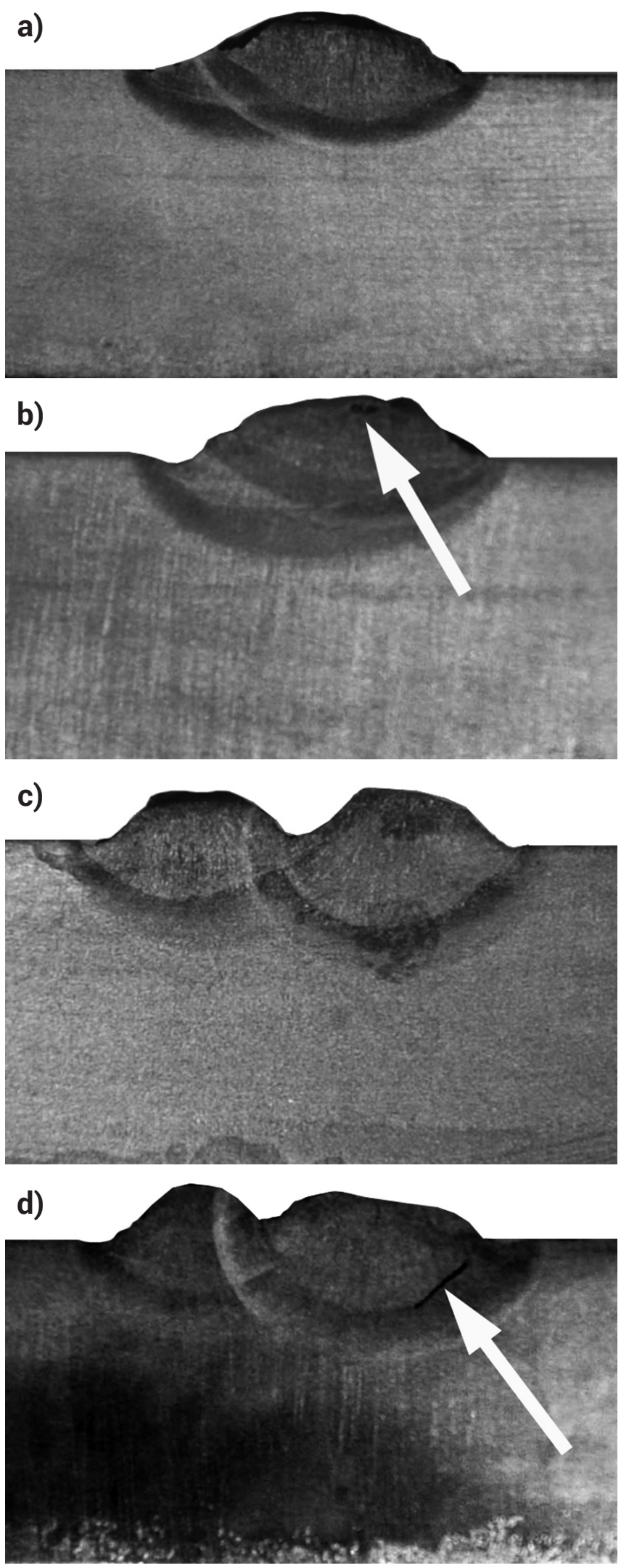

Rys. 2. Przekroje napoin próbnych: a) Próbka TBW1 - podziałka $50 \%$; b) Próbka TBW2 - podziałka 75\%: strzałką zaznaczono pęcherz gazowy; c) Próbka TBW2 - podziałka 11\%; d) Próbka TBW2 - podziałka $21 \%$ : strzałką zaznaczono pęknięcie wzdłuż linii wtopienia. Traw. Nital Fig. 2. Cross-section of test padding welds: a) TBW1 - pitch $50 \%$; b) TBW2 with gas pore - pitch 75\%; c) TBW2 pitch - 11\%; d) TBW2 with crack in fusion line - pitch $21 \%$. Etch. Nital

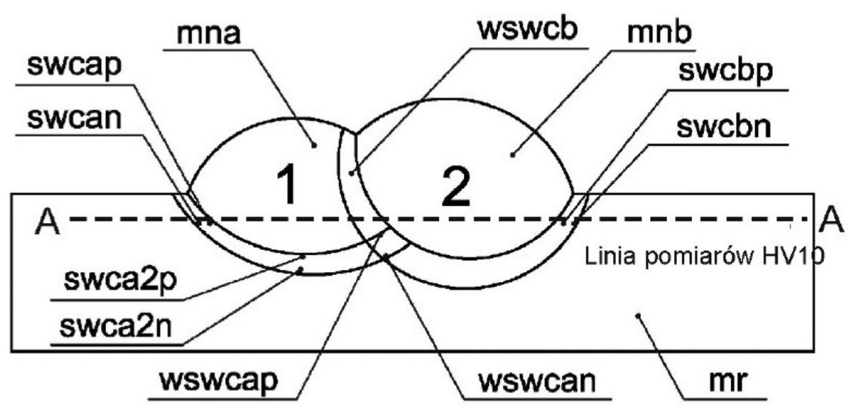

Rys. 3. Lokalizacja i oznaczenia badanych stref napoin: $\mathrm{mr}$ - materiał rodzimy, mna - napoina pierwsza, mnb - napoina druga, swca - SWC napoiny pierwszej, swcb - SWC napoiny drugiej, wswca - strefa zachodzących na siebie swca i swcb, wswcb - strefa swcb zachodząca w strefę mna, $\mathrm{n}$ - strefa normalizacji, $\mathrm{p}$ - strefa przegrzania Fig. 3. Location and designation of investigated zones at test plate: $\mathrm{mr}$ - base material, mna - first padding weld, mnb - second padding weld, swca - HAZ of first padding weld, swcb - HAZ of second padding weld, wswca - swca and swcb overlap area, wswcb - swcb overlap in $\mathrm{mna}, \mathrm{n}$ - standardization area, $\mathrm{p}$ - overheated area
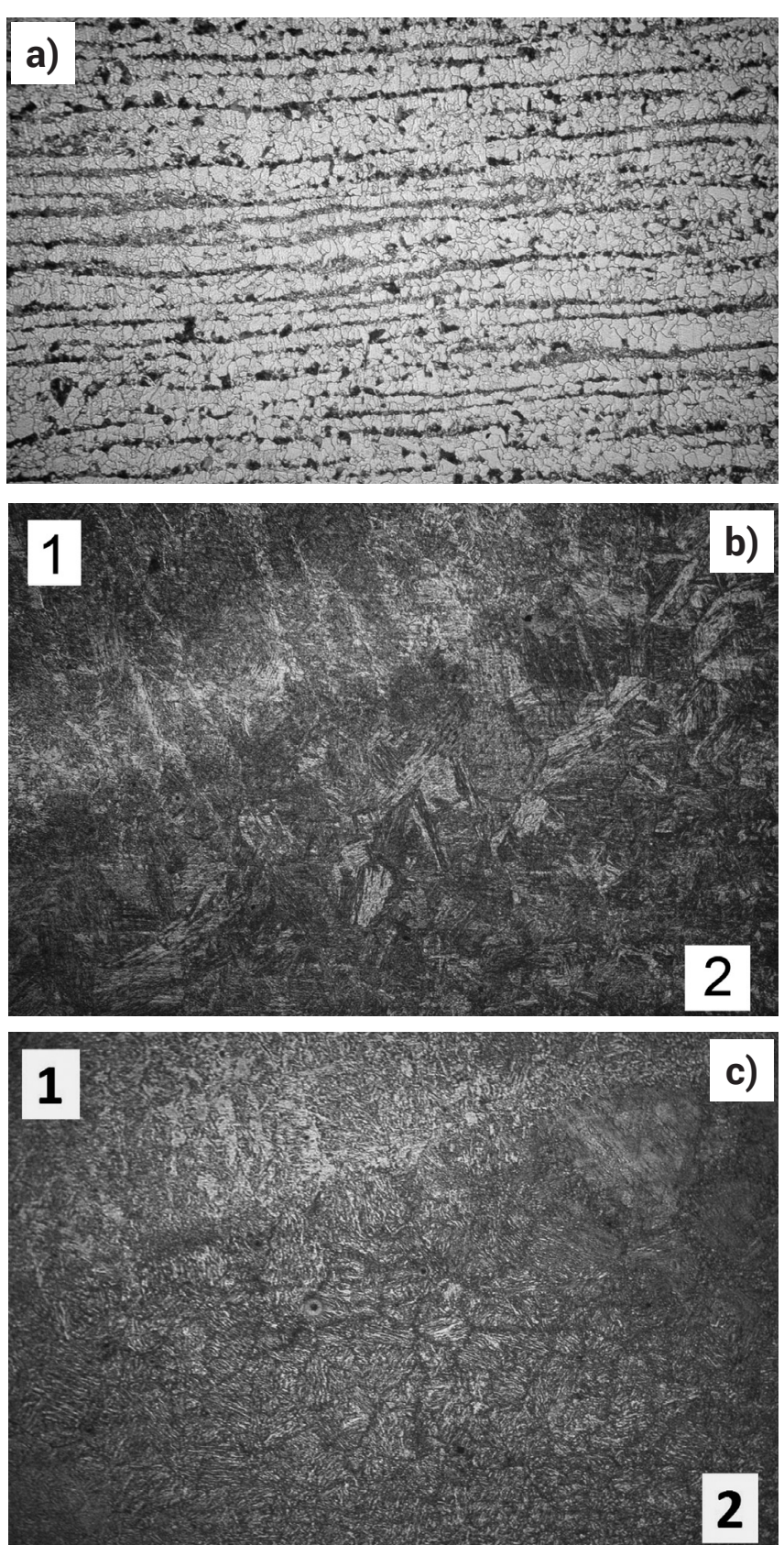

Rys. 4. Charakterystyczne mikrostruktury próbki napawanej: a) materiał rodzimy; b) 1 - mna, 2 - swca; c) 1 - wswcb, 2 - wswca. Pow. 200x Fig. 4. Microstructure of sample: a) base material; b) $1-$ mna, 2 - swca; c) 1 - wswcb; 2 - wswca. Magn. 200x 
Na rysunku 4 przedstawiono struktury materiału rodzimego, napoiny i SWC. Stal S355G10+N charakteryzuje się drobnoziarnistą strukturą ferrytyczno-perlityczną z wyraźną pasmowością. Mikrostruktura obu napoin (podstawowej i odpuszczającej) jest podobna i składa się z ferrytu w układzie kolumnowym z zarysem struktury Widmannstättena. W strefie wpływu ciepła stwierdzono występowanie iglastych struktury hartowniczych.

\section{Pomiary twardości}

Pomiary twardości wykonano zgodnie z zaleceniami PN-EN ISO 9015-1 [18] metodą Vickersa na przekrojach poprzecznych wszystkich próbek z siłą obciążającą wgłębnik równą 98 N (HV10). Pomiary wykonano w linii (A-A) przebiegającej $2 \mathrm{~mm}$ poniżej lica napoin oraz $\mathrm{w}$ obszarze swca2n i swca2p (rys. 3). Wybrane rozkłady twardości zaprezentowano na rysunku 5. Twardość maksymalna SWC napoin w obszarach nie poddanych oddziaływaniu kolejnego cyklu cieplnego przekracza przyjętą zgodnie z PN-EN ISO 15614-1 [19] wartość graniczną 380HV10 i wynosiła

a)

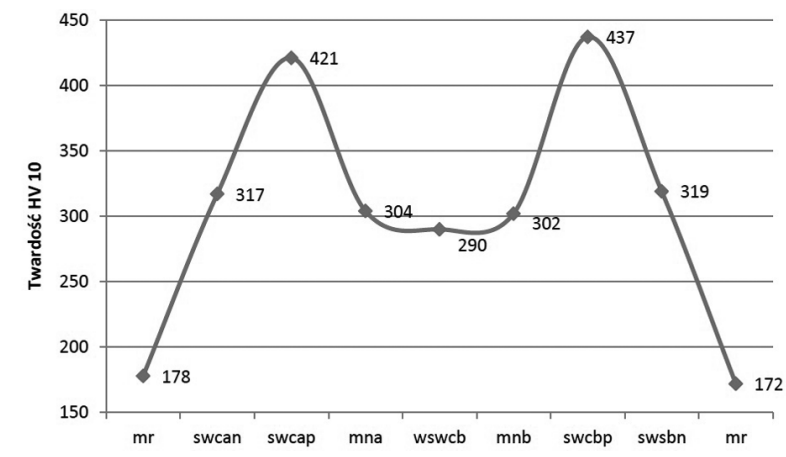

c)

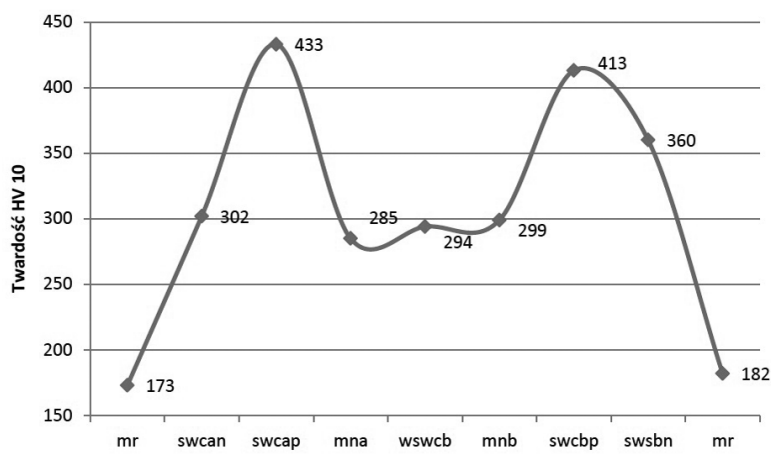

odpowiednio 437HV10 i 433HV10 dla próbek TBW1 i TBW2. Na rysunku 6 pokazano zależność twardości w SWC pierwszej napoiny (odpuszczonej) w obszarze podściegowym (swca2p i swca2n) od podziałki ściegu odpuszczającego. Na tej podstawie wyznaczono najbardziej korzystną wartość podziałki dla badanej stali, która mieści się w zakresie $75 \div 100 \%$.

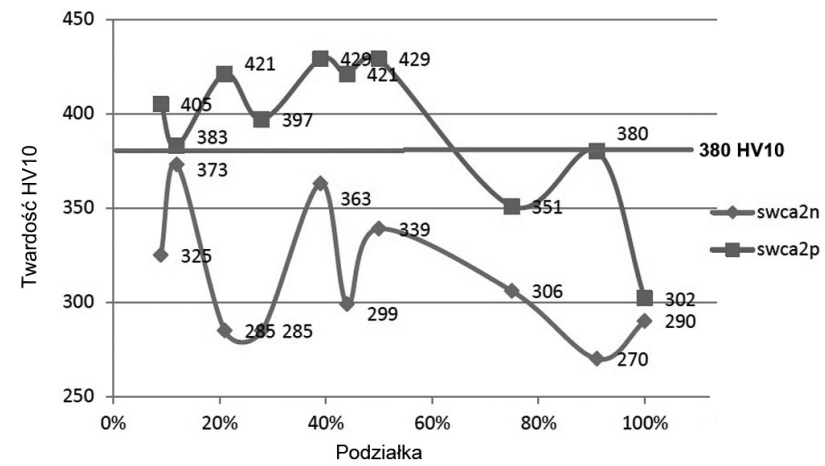

Rys. 6. Zależność twardości stref swca2n i swca2p napoin od podziałki Fig. 6. Dependence of hardness of swca2n i swca2p padding weld zones on pitch b)

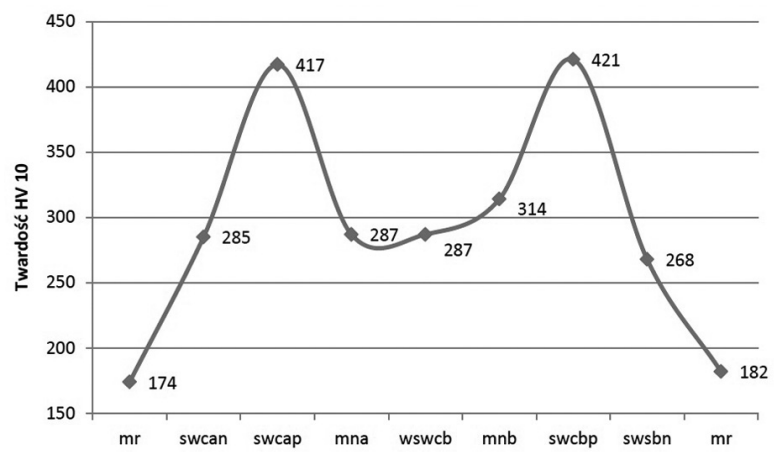

d)

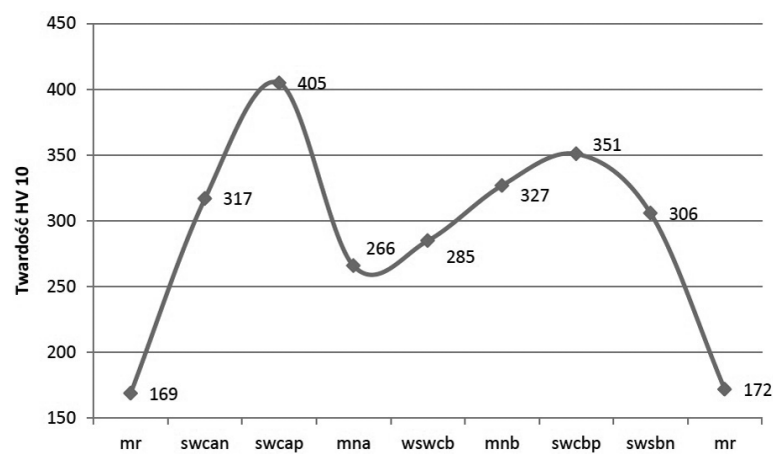

Rys. 5. Rozkład twardości na przekroju napoin: a) próbka TBW1, podziałka 9\%; b) próbka TBW1, podziałka 21\%; c) próbka TBW2, podziałka $39 \%$; d) próbka TBW2, podziałka $75 \%$

Fig. 5. Hardness distribution across: a) sample TBW1, pitch 9\%; b) sample TBW1, pitch 21\%; c) sample TBW2, pitch 39\%; d) sample TBW2, pitch 75\%

\section{Podsumowanie}

W pracy podjęto badania w kierunku sprawdzenia przydatności zastosowania techniki ściegu odpuszczającego do poprawienia spawalności stali S355G10+N pod wodą. Badana stal charakteryzuje się w warunkach spawania mokrego elektrodami otulonymi ograniczoną spawalnością, o czym świadczy obecność pęknięć zimnych (rys. 2d). Jednak pomiary twardości wykazały, że w SWC napoin próbnych poddanych oddziaływaniu ciepła pochodzącego ze ściegu odpuszczającego twardość znacząco spadała, a maksymalna twardość w pewnym zakresie podziałki nie przekracza granicznej wartości 380HV10. Pozwoliło to na określenie optymalnej z punktu widzenia spawalności wartości podziałki dla ściegów odpuszczających w zakresie $75 \div 100 \%$. Próbki z wyznaczoną podziałką spełniają kryterium akceptacji wymagań w zakresie twardości zgodnie z wytycznymi PN-EN ISO 15614-1 [19].

Z analizy wyników badań można wywnioskować, że zastosowanie techniki ściegu odpuszczającego w przypadku stali S355G10+N pozwoli na wykonywanie złączy spawanych spełniających kryteria przepisów odbiorowych: norm 
przedmiotowych oraz wytycznych towarzystw klasyfikacyjnych. Spawanie z zachowaniem wyznaczonych parametrów i warunków może zostać zastosowane w naprawach konstrukcji podmorskich zbudowanych z badanej stali. Należy zaznaczyć, że skuteczność zastosowania techniki ściegów odpuszczających może zależeć również od innych, nie badanych dotychczas zmiennych, np.: pozycji spawania, kąta ustawienia elektrody, czy zasolenia wody. Ograniczeniem zastosowania rozpatrywanej techniki jest konieczność zachowania powtarzalności procesu, co w przypadku spawania mokrego w środowisku wodnym jest szczególnie trudne. Kolejne badania i analizy powinny uwzględniać te czynniki, ponieważ pozwoliłoby to na kompleksowe określenie właściwych warunków stosowania techniki ściegu odpuszczającego przy spawaniu pod wodą.

\section{Wnioski}

Zastosowanie techniki ściegu odpuszczającego jest skuteczną metodą poprawy spawalności stali S355G10+N w warunkach spawania mokrego elektrodami otulonymi.

Oddziaływanie ciepła ściegu odpuszczającego spowodowało obniżenie twardości maksymalnej SWC napoin próbnych poniżej wartości krytycznej 380 HV, dzięki czemu zostało spełnione kryterium PN-EN ISO 15614-1.

Określono najkorzystniejsze z punktu widzenia spawalności stali wartości podziałki w zakresie $75 \div 100 \%$.

\section{Literatura}

[1] Fydrych D., Rogalski G, Łabanowski J.: Problems of underwater welding of higher-strength low alloy steels. Institute of Welding Bulletin $5 / 2014$.

[2] Łabanowski J., Fydrych D., Rogalski G.: Underwater welding - a review. Advances in Materials Science $3 / 2008$.

[3] Fydrych D.: Pękanie zimne stali spawanej w środowisku wodnym. Przegląd Spawalnictwa 10/2012.

[4] Gao W., Wang D., Cheng F., Deng C., Liu Y., Xu W.: Enhancement of the fatigue strength of underwater wet welds by grinding and ultrasonic impact treatment. Journal of Materials Processing Technology 223/2015.

[5] Guo N., Yang Z., Wang M., Yuan X., Feng J.: Microstructure and mechanical properties of an underwater wet welded dissimilar ferritic/ austenitic steel joint. Strength of Materials 1/2015.

[6] Fydrych D., Łabanowski J., Rogalski G.: Weldability of high strength steels in wet welding conditions. Polish Maritime Research 2/2013.

[7] Fydrych D., Rogalski G., Tomków J., Łabanowski J.: Skłonność do tworzenia pęknięć zimnych złączy ze stali S420G2+M spawanej pod wodą metodą mokrą. Przegląd Spawalnictwa 10/2013.

[8] Fydrych D., Łabanowski J., Rogalski G., Haras J., Tomków J., Świerczyńska A., Jakóbczak P., Kostro $Ł$.: Weldability of S500MC steel in underwater conditions. Advances in Materials Science, 2/2014.

[9] Maksimov S.Y.: Предотвращение холодных трещин в зоне термического влияния при сварке под водой низколегированных сталей повышенной прочности. Збірник Наукових Праць НУК 4/2014.

[10] Garašić I., Kralj S., Kožuh Z.: Investigation into cold cracking in underwater wet welding of API $5 \mathrm{~L}$ X70 steel. Transactions of FAMENA $3 / 2009$.
[11] Fydrych D., Łabanowski J.: Zastosowanie techniki ściegu odpuszczającego do spawania mokrego. Przegląd Spawalnictwa 2/2013.

[12] Grubbs C.E.: Joint industry underwater welding development program. Phase I - final report. Global Divers \& Contractors, Colorado School of Mines, 1995.

[13] Łomozik M.: Morfologia i własności plastyczne obszarów strefy wpływu ciepła w stalowych złączach spawanych w aspekcie użycia ściegów odpuszczających. Uczelniane Wydawnictwa Naukowo-Dydaktyczne AGH, Kraków 2007.

[14] Aloraier A., Ibrahim R., Thomson P.: FCAW process to avoid the use of post weld heat treatment. International Journal of Pressure Vessels and Piping 5/2006.

[15] Kwieciński K., Łomozik M., Urzynicok M., Mariani P.: Welding new generation steel PB2 using conventional welding with and without PWHT with use of temper bead technique. Proceedings of Design, Fabrication and Economy of Metal Structures Conference, 24-26 April 2013, Miscolc Hungary.

[16] PN-EN 10225:2011 Stale konstrukcyjne spawalne na nieruchome konstrukcje przybrzeżno-morskie. Warunki techniczne dostawy.

[17] PN-EN ISO 17639:2013-12 Badania niszczące spawanych złączy metali. Badania makroskopowe i mikroskopowe złączy spawanych.

[18] PN-EN ISO 9015-1:2011 Badania niszczące złączy spawanych metali. Badanie twardości. Część 1: Badanie twardości złączy spawanych łukowo.

[19] PN-EN ISO 15614-1:2008 Specyfikacja i kwalifikowanie technologii spawania metali. Badanie technologii spawania. Część 1: Spawanie łukowe i gazowe stali oraz spawanie łukowe niklu i stopów niklu. 